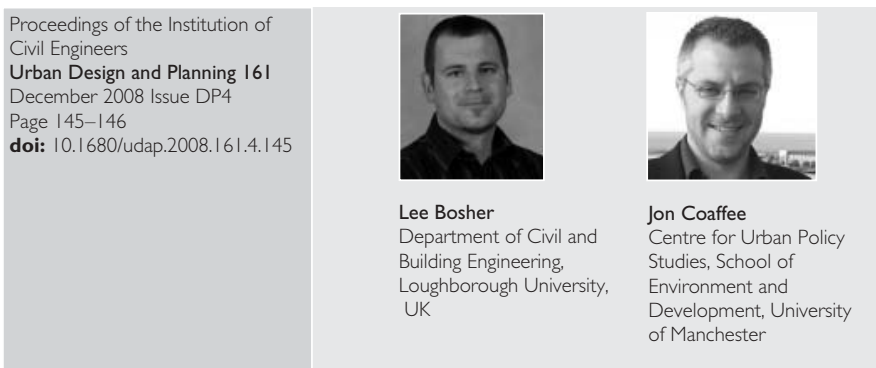

\title{
Editorial: International perspectives on urban resilience
}

\section{Bosher PhD, FRGS, FICDDS and J. Coaffee PhD}

During the last few years a number of high profile disasters, such as the Asian tsunami (2004), the Kashmir (2005) and Sichuan (2008) earthquakes and hurricanes Katrina (2005) and Ike (2008), as well as a number of high profile terrorist attacks, have stimulated theoretical developments in relation to the way in which disasters can be avoided and managed. It is in light of these developments that the discourse of 'resilience' now resonates throughout many international bodies as well as national governments and the disciplines involved with the mitigation of natural and human induced hazards. It is this new perspective that has helped to bring 'urban resilience' and the roles of built environment professionals into the spotlight.

It has been suggested that professionals involved in the planning, design and construction of the built environment need to become more involved in 'disaster risk management'. A common definition of disaster risk management is:

a systematic process of using administrative decisions, organization, operational skills and capacities to implement policies, strategies and coping capacities of the society and communities to lessen the impacts of natural hazards and related environmental and technological disasters. ${ }^{2}$

Although the concept of disaster risk management is traceable back to the beginning of the 20th century, it is gradually becoming institutionalised. This is a product of social science research perspectives leading to the realisation that the impact of a natural or human-induced hazard mostly depends on the capacity of people to absorb the impact and quickly recover from loss or damage. The resultant shift of focus has been towards understanding social and economic vulnerability and has contributed to the shift towards 'bottom-up', community based and sustainable long-term developmental initiatives in ensuring resilience can be attained. It is this perspective that cross-cuts the multidisciplinary focus of this special issue.

The concept of resilience furst emerged in research concerned with how ecological systems cope with stresses or disturbances caused by external factors, ${ }^{3}$ but has more recently been applied to human social systems, ${ }^{4}$ economic recovery, ${ }^{5}$ engineering ${ }^{6}$ and urban planning and recovery after calamitous events. ${ }^{7}$ Coaffee $^{8}$ has argued that there are three key dimensions which differentiate resilience from traditional notions of disaster planning and recovery. Firstly, the emphasis is on preparedness rather than post-disaster management. Secondly, there has been a widening of the emergency planning agenda to embrace security challenges in addition to natural hazards and technological accidents. The third dimension concerns the role of institutional resilience to protect key infrastructural systems. This has necessarily broadened out the range of experts and professions whose input must now be garnered and integrated into the resilience effort. Consequently, Bosher has suggested that a resilient built environment

should be designed, located, built, operated and maintained in a way that maximises the ability of built assets, associated support systems (physical and institutional) and the people that reside or work within the built assets, to withstand, recover from, and mitigate for, the impacts of extreme natural and human-induced hazards. ${ }^{9}$

This special issue of Urban Design and Planning includes articles that cover a variety of perspectives on urban resilience, incorporating associated physical, social, economic and institutional issues. Iain White, in illustrating what he terms the 'absorbent city', highlights how engineered defence against flooding has expanded in recent years, particularly in the UK, as concerns with reducing the impact of climate change and developing a host of mitigation measures to boost urban resilience have been stimulated. Christine Wamsler focuses upon how local and community resilience strategies have aided the disaster recovery effort in El Salvador. It is argued that governmental and non-governmental organisations should develop a more nuanced approach to improving urban resilience through reconstruction and development aid, and human settlement planning, through a better understanding of the strategies already embedded within local and community networks for coping with disaster-related risk. The third paper by Paul 0'Hare and Jon Coaffee focuses upon an increasingly emergent theme in overall resiliency agendas - counterterrorism. They highlight how built environment professionals are increasingly being given extra responsibility for designingin counter-terror features to buildings and public spaces. This, it is argued, poses a series of ethical issues for professional planners. Using examples from the UK they highlight how coping with the threat of terrorism is now catalysing increased effort and expenditure on broader urban resilience strategies and plans. 
Zeeshan Aziz and his colleagues at the University of Illinois highlight the multiple contributions that civil engineers can make to the disaster recovery effort with a particular focus upon building assessment. They unpack the deficiencies of often-utilised technology to coordinate such responses before outlining the possibilities of a new mobile-IT based collaborative framework to facilitate more effective and coordinated disaster response and recovery operations. In the final paper of this issue Ilan Kelman, using examples from Boulder in Colorado, focuses upon the idea of 'relocalisation' in order to highlight the importance of locally produced and owned disaster risk management efforts. It is proposed that this is done through the lens of 'good governance', which is seen to involve the principles of participation, transparency, accountability, rule of law, effectiveness, and equity. Central to the paper however is the realisation that fiscal retrenchment often makes it difficult to sustain disaster risk management programmes at local levels despite community support.

The key messages from this issue are that 'urban resilience' is of growing importance in design, planning and civil engineering and that it should be developed in a transdisciplinary way; incorporating a wide range of stakeholders involved with the structural and non-structural approaches that are required to attain urban resilience.

\section{REFERENCES}

1. Bosher L. S., Dainty A. R. J., Carrillo P. M., Glass J. And PRICE A. D. F. Integrating disaster risk management into construction: A UK perspective. Building Research \& Information, 2007, 35, No. 2, 163-177.

2. UN/ISDR. Living with Risk: A Global Review of Disaster Reduction Initiatives, United Nations International Strategy for Disaster Reduction, Geneva, 2004.

3. Holling C. S. Resilience and stability of ecological systems, Annual Review of Ecology and Systematics, 1973, 4, 2-23.

4. Agar W. N. Social and Ecological Resilience: Are They Related?', Progress in Human Geography, 2000, 24, No. 3, 347-64.

5. Rose A. Defining and Measuring Economic Resilience to Disasters, Disaster Prevention and Management, 2004, 13, No. 4, 307-314.

6. Gunderson L., Holling C. S., Pritchard L., and Peterson G. D. Resilience: In Mooney H. A. and Canadell J. G. (eds), The Earth system: biological and ecological dimensions of global environmental change, John Wiley \& Sons Ltd, Chichester, 2002, 2.

7. Vale L. J. and Campanella T. J. (eds). The Resilient City: How Modern Cities Recover from Disaster, Oxford University Press, Oxford, 2005.

8. Coaffee, J. Security planning in the resilient city: Hazards and the Built Environment: Attaining Built-in Resilience, (Bosher L. S. (ed.)) Taylor and Francis, London, 2008, 300-317.

9. Bosher L. S. Introduction: The need for built-in resilience. Hazards and the Built Environment: Attaining Built-in Resilience. (Bosher L. S. (ed.)) Taylor and Francis, London, 2008, 13. 